\title{
CRIANÇA, ESCOLA E ACOLHIMENTO INSTITUCIONAL: a escola como espaço de socialização
}

\author{
Maria Vitória Braga Sudario \\ Gilmara Lupion Moreno
}

\section{Resumo}

O artigo versa sobre o papel da escola na socialização das crianças acolhidas institucionalmente. Elencouse como objetivos pesquisar sobre o papel da escola no processo de construção da identidade e da socialização da criança acolhida; conhecer a trajetória da criação, implementação e consolidação das instituições de acolhimento no Brasil; e reconhecer a escola como importante espaço de socialização. Quanto à metodologia, trata-se de uma pesquisa qualitativa do tipo bibliográfica. Como resultado, percebeuse a importância do conhecimento sobre a história e a função das instituições de acolhimento, a fim de desmistificar mitos e preconceitos; assim como a relevância do papel da escola na infância das crianças acolhidas. A escola tem o papel de ajudá-las na superação das possíveis dificuldades em seu desenvolvimento, e desmistificar a visão, muitas vezes, preconceituosa sobre a criança acolhida.

Palavras-chave: acolhimento institucional; escola; criança.

\section{CHILD, SCHOOL AND INSTITUTIONAL SHELTER: school as a space of socialization}

\begin{abstract}
This article is about the role of school in the socialization of foster children in foster care institutions. The objectives were to investigate the role of the school in the process of building the identity and socialization of the foster children; to know the trajectory of the creation, implementation and consolidation of foster care institutions in Brazil; and to recognize the school as an important space for socialization. As for the methodology, this is a qualitative bibliographical research. As a result, it was possible to realize the importance of knowledge about the history and function of the foster care institutions, in order to demystify myths and prejudices; as well as the the relevance of the role of the school in the childhood of the foster children. The school has the role of helping them overcome possible difficulties in their development, and demystifying common stereotypes about the foster child.
\end{abstract}

Keywords: institutional shelter; school; child.

\section{EL NIÑO, LA ESCUELA Y LA ACOGIMIENTO INSTITUCIONAL:}

la escuela como espacio de socialización

Resumen

Este artículo trata del papel de la escuela en la socialización de los niños de acogida en instituiciones. Sus objetivos son investigar el papel de la escuela en el proceso de construcción de la identidad y socialización del niño de acogida; conocer la trayectoria de creación, implementación y consolidación de las instituciones de acogida en Brasil; y reconocer a la escuela como un importante espacio de socialización. En cuanto a la metodología, se trata de una investigación cualitativa. Como resultado, fue posible darse cuenta de la importancia de conocer la historia y la función de las instituciones de acogida, para desmitificar mitos y prejuicios; así como la relevancia del papel de la escuela en la infancia de los niños de acogida. La escuela tiene el papel de ayudarles a superar las posibles dificultades en su desarrollo, y desmitificar la visión, a menudo prejuiciosa, del niño acogido. 
Palabras clave: acogimiento institucional; escuela; niño.

\section{INTRODUÇÃO}

Este trabalho trata sobre a importância da escola para a socialização e desenvolvimento das crianças, em especial, as que se encontram institucionalizadas. A primeira socialização do indivíduo é feita pela família, processo que "inicia-se com o nascimento e, embora sujeito a mudanças, permanece ao longo de todo ciclo vital" (BORSA, 2007, p. 1). Entretanto, as crianças e adolescentes afastados de suas famílias por medida protetiva ficam acolhidos institucionalmente até que estas sejam reajustadas, e problemas como drogadição, violência etc. sejam cessados. Quando da inviabilidade do retorno das crianças e adolescentes às famílias de origem, propõe-se o encaminhamento a uma família adotiva.

Com isso, é necessário o apoio da escola e de psicólogos para que essas transições de um lugar para outro sejam feitas da forma menos traumática possível, pois elas podem dificultar as relações afetivas e de socialização das crianças e adolescentes. Portanto, "a escola é, junto com a família, a instituição social que maiores repercussões têm para a criança. A escola não só intervém na transmissão do saber científico organizado culturalmente como influi em todos os aspectos relativos aos processos de socialização e individuação da criança [...]" (PALACIOS, 1995 apud BORSA, 2007, p. 4). Mas, o que a escola em parceria com as instituições de acolhimento pode desenvolver para a melhoria do processo de socialização? Qual o papel da escola na educação das crianças acolhidas?

Desse modo, elencou-se como objetivo geral deste estudo pesquisar sobre o papel da escola na educação das crianças acolhidas. Como objetivos específicos pretendeu-se traçar um breve histórico da criação, implementação e consolidação das instituições de acolhimento no Brasil e reconhecer a escola como importante espaço de socialização, bem como sua função junto às crianças acolhidas. Quanto à metodologia, trata-se de uma pesquisa qualitativa do tipo bibliográfica, realizada por meio de levantamento de referências teóricas publicadas em suportes físicos e eletrônicos, como livros, artigos científicos, e websites, o que nos possibilitou uma melhor compreensão de um grupo social, a fim de produzir informações aprofundadas sobre o tema. Informa-se, ainda, que este artigo é fruto de um Trabalho de Conclusão de Curso vinculado aos projetos de pesquisa e extensão, que tratam sobre escola, adoção e acolhimento institucional, ambos de uma universidade pública do Estado do Paraná.

A seguir, apresentaremos os resultados deste estudo. A saber, num primeiro momento, abordaremos a trajetória histórica das instituições de acolhimento no Brasil, desde seu surgimento em meados do século XVIII, com a roda dos expostos, até os dias atuais. Em seguida, trataremos sobre o papel da escola como espaço de socialização das crianças acolhidas.

\section{A trajetória histórica das instituições de acolhimento no Brasil}

Nesse primeiro momento, faremos um breve relato acerca da trajetória das instituições de acolhimento também conhecidas como abrigos, desde sua implementação e consolidação até os dias atuais. De acordo com Moura (2004), Torres (2008) e Marcílio (1997), o surgimento da visão de acolhimento no Brasil aparece em meados do século XVIII, e eram as igrejas católicas que cuidavam do acolhimento infantil. Com a necessidade de um lugar onde pudesse deixar as crianças cujas mães não podiam criá-las, o Papa Inocêncio III implantou em Portugal, na Casa de Misericórdia durante a Idade Média, a roda dos expostos, iniciativa que só chegou no Brasil em 1726, implantada na Santa Casa da Misericórdia em Salvador, na Bahia. 
A roda dos expostos, também conhecida como roda dos excluídos, consistia em uma porta giratória, onde o adulto colocava o bebê na parte externa e a girava para que ele fosse para a parte interna, garantindo o sigilo da identidade da pessoa que deixava a criança na roda. O motivo que levava ao abandono dessas crianças era o fato de que muitas famílias não tinham condições financeiras de mantê-las; eram filhos de mães solteiras, filhos ilegítimos considerados filhos do pecado, que viviam em condições de miséria e também filhos de escravas que, com o Alvará de 31 de janeiro de 1775, se fossem ali deixados, seriam livres da escravidão (MOURA, 2004). A roda dos expostos tinha caráter assistencialista: as crianças chegavam e recebiam os devidos cuidados de higienização e alimentação e, em seguida, eram encaminhadas para as amas de leite ou famílias que não tinham filhos para serem cuidadas até os sete anos de idade. Depois, eram encaminhadas para trabalhar, os meninos como aprendizes e as meninas como domésticas (KREUZ, 2011).

Apesar da preocupação com a criança, as instituições apresentavam práticas inadequadas de maus tratos, viviam em condições precárias, eram superlotadas, demonstrando uma forma ineficiente no cuidado com as crianças e adolescentes. Ainda assim, a roda dos expostos se mantivera por dois séculos, com o intuito de conter “[...] o grande número de infanticídios; possibilitar aos cristãos praticarem a caridade ao próximo, já que a igreja era tida como principal responsável pelos cuidados dos mais necessitados; como também, proporcionar à sociedade um local para esconder os filhos nascidos fora do casamento" (PEREIRA, 2006 apud ALEXANDRE, 2017, p. 28).

Em 1927, foi concebido o Código de Menores, denominado Código Mello Mattos, primeiro documento que trata sobre a criança e o adolescente abandonado, proibindo o sistema da roda dos expostos, e que os menores abandonados e deliquentes deveriam ser entregues ao abrigo com seu registro de nascimento, passando a ser responsabilidade legal do Estado a tutela do menor abandonado (BRASIL, 1927). Apesar de mostrar alguma preocupação com a infância das crianças, o Código de Mello Mattos deprecia a imagem desse menor, apontando-o como delinquente, perigoso, sem ninguém para se importar e cuidar dele. Suas famílias pobres, na maioria negras, sem formação ou qualificação profissional, sem espaços fixos para morar, eram vistas pela sociedade como incompetentes e despreparadas para cuidar de uma criança.

Os reformatórios tinham o propósito de disciplinar, educar e recolher os menores abandonados que ameaçavam a ordem pública, onde preparavam os meninos e meninas para o trabalho. Trabalho industrial, no caso dos meninos, e afazeres domésticos para as meninas. Da mesma forma, ensinavam as crianças sobre a educação moral. Esses asilos/reformatórios tinham uma ideia de confinamento, contenção espacial, controle do tempo, submissão e autoridade (NAZARIO, 2014). Essa política assistencialista que culminou na criação dos abrigos no início do século XX, deu-se pelo objetivo de higienizar a população, retirar do convívio social o problema que colocava em risco a ordem social, ou seja, colocar os menores em instituições fechadas, afastados do convívio social (RIZZINI; RIZZINI, 2004).

Em 1942 é criado o Serviço de Assistência ao Menor (SAM), conhecido como a primeira política pública estruturada para a infância e adolescência no Brasil, destinado a menores de 18 anos, com o objetivo de corrigir os adolescentes e educá-los. Entretanto, dada a sua ineficiência, em substituição ao SAM, no ano de 1964, em meio à ditadura militar, foi criada a Fundação Nacional do Bem-Estar do Menor (FUNABEM). O objetivo era implementar políticas de bemestar do menor, através da elaboração de diretrizes e técnicas, consecutivamente originando a criação da Fundação Estadual do Bem-Estar do Menor (FEBEM), que tinha o objetivo de cuidar do bem-estar do menor. No entanto, foi motivo de revoltas pela sua superlotação e violências baseadas na disciplina militar aos menores que cumpriam medida socioeducativa. Dentro desse espaço, circulavam crianças que foram institucionalizadas por questões de negligência e violência 
junto às crianças que descumpriam as leis, sem separação, como afirmado por Kreuz (2011), transformando menores abandonados em delinquentes.

Com as denúncias de violências, em 1976, foi criada a Comissão Parlamentar de Inquérito (CPI), que investigou as instituições de acolhimento, resultando na reelaboração do Novo Código de Menores em 1979 (BRASIL, 1979), que previa a internação das crianças nas instituições e, consequentemente, o afastamento do convívio social para melhor correção de seu comportamento, ainda pregando uma abordagem punitiva. Foi só a partir da década de 1980 que pudemos ver algum avanço na institucionalização das crianças, com críticas feitas aos modelos existentes e preocupação com as crianças e adolescentes, criando, em 1986, a Comissão da Criança Constituinte e, em 1988, a inclusão na Nova Constituição Federal do Art. 226, que considera a família como base da sociedade, e do Art. 228, que assegura os direitos fundamentais à criança e ao adolescente (BRASIL, 1988).

Em 1990, houve a aprovação do Estatuto da Criança e do Adolescente (ECA) (BRASIL, 1990), prevendo novas práticas de atendimento e, o mais importante, a concepção da criança e do adolescente como seres de direitos, e da família e da sociedade como referências na constituição da criança e do adolescente. Houve algumas mudanças, dentre elas, a FEBEM deixou de atender adolescentes carentes, passando a atender apenas os adolescentes em conflito com a Lei. Hoje em dia, a FEBEM é conhecida como Fundação Centro de Atendimento Socioeducativo ao Adolescente (CASA), que "tem a missão primordial de aplicar medidas socioeducativas de acordo com as diretrizes e normas previstas no Estatuto da Criança e do Adolescente (ECA) e no Sistema Nacional de Atendimento Socioeducativo (SINASE)" (FUNDAÇÃO CASA, 2021, p. 1).

Com a aprovação do ECA e a criação do Plano Nacional da Convivência Familiar e Comunitária (PNCFC) em dezembro de 2006 (BRASIL, 2006), a criança e o adolescentes passam a ser vistos como sujeitos de direito. Isso reforçou a preservação dos vínculos familiares e comunitários vistos como eixos importantes do desenvolvimento integral da criança, dando início à reestruturação dos grandes abrigos em casas pequenas, com menor grupo de crianças e adolescentes, em consonância com o documento de Orientações Técnicas: Serviços de Acolhimento para Crianças e Adolescentes, aprovado em 2009 (BRASIL, 2009a), que teve como finalidade regulamentar a organização e a oferta dos serviços de acolhimento. Segundo o documento, o acolhimento de caráter provisório e excepcional deve atender crianças e adolescentes de ambos os sexos,

[...] inclusive crianças e adolescentes com deficiência, sob medida de proteção (Art. 98 do Estatuto da Criança e do Adolescente) e em situação de risco pessoal e social, cujas famílias ou responsáveis encontrem-se temporariamente impossibilitados de cumprir sua função de cuidado e proteção. [...] $\mathrm{O}$ acolhimento será feito até que seja possível o retorno à família de origem (nuclear ou extensa) ou colocação em família substituta (BRASIL, 2009b, p. 30).

Antes do ECA, os termos utilizados para referir-se ao serviço de acolhimento eram orfanatos, internatos ou reformatórios. A partir do ECA, o termo utilizado passou a ser abrigo. Após a aprovação das Orientações Técnicas: Serviços de Acolhimento para Crianças e Adolescentes (BRASIL, 2009a), o termo utilizado passou a ser serviços de acolhimento, que podem ser ofertados em diferentes tipos de espaços, sendo eles: Abrigos Institucionais, Casas Lares, Família Acolhedora e Repúblicas. Segundo as orientações em vigor, a instituição de acolhimento:

[...] deve ter aspecto semelhante ao de uma residência e estar inserido na comunidade, em áreas residenciais, oferecendo ambiente acolhedor e condições institucionais para o atendimento com padrões de dignidade. Deve ofertar 
atendimento personalizado e em pequenos grupos e favorecer o convívio familiar e comunitário das crianças e adolescentes atendidos, bem como a utilização dos equipamentos e serviços disponíveis na comunidade local (BRASIL, 2009a, p. 63).

O Acolhimento Institucional deve oferecer serviço de acolhimento provisório até que as crianças e adolescentes que estão com medida protetiva possam retornar à convivência com sua família de origem ou encaminhadas a uma família substituta, ou seja, à adoção. Além disso, tem capacidade máxima de 20 (vinte) crianças e adolescentes de 0 a 18 anos. Conta com equipe profissional de coordenador, equipe técnica, educador/cuidador e auxiliar de educador/cuidador, e sua infraestrutura deve contar com quartos, sala de estar, sala de jantar, ambiente para estudos, banheiro, cozinha, área externa com jardim, quintal, sala para a equipe técnica poder trabalhar, sala de coordenação e sala de reuniões (BRASIL, 2009a).

A Casa Lar assemelha-se a uma residência qualquer, no entanto, temporária, e busca inserir as crianças e adolescentes no espaço familiar com uma rotina o mais normal possível, oferecendolhes atenção, afeto e cuidado. Com capacidade máxima de 10 crianças e adolescentes em idades de 0 a 18 anos, o diferencial é de que nela reside uma cuidadora ou casal cuidador que será responsável pelas crianças e adolescentes, e que terá participação ativa na organização da rotina da casa e na vida deles, como em reuniões escolares (BRASIL, 2009a).

Já o serviço de acolhimento em Família Acolhedora, programa proporcionado pelo Ministério do Desenvolvimento Social (MDS) e pelo Programa de Combate à Fome/Projeto Caminho para Casa, prevê o acompanhamento das famílias pelo Centro de Referência de Assistência Social (CRAS) e pelo Centro de Referência Especializado de Assistência Social (CREAS), e prevê a implantação no Sistema Nacional de Adoção (SNA). Nesse serviço, o acolhimento de crianças e adolescentes ocorre na residência de famílias cadastradas no programa e capacitadas, preferencialmente, no município em que a criança reside, salvo exceções de afastamento. "Cada família acolhedora deverá acolher uma criança/adolescente por vez, exceto quando se tratar de grupo de irmãos, quando esse número poderá ser ampliado" (BRASIL, 2009a, p. 77).

A Família acolhedora não deve ser confundida com a adoção, portanto, é necessária uma preparação da criança ou adolescente que será inserido nesse meio, e também da família que irá recebê-lo, para que não ocorra mal-entendidos. Este tipo de acolhimento "é feito por meio de um termo de guarda provisória, solicitado pelo serviço de acolhimento e emitido pela autoridade judiciária para a família acolhedora previamente cadastrada” (BRASIL, 2009a, p. 77).

Todos os casos de acolhimento devem seguir os princípios descritos no ECA, de espaços temporários que possuem o intuito de reinserção em vivência familiar, até a reintegração da criança e do adolescente à sua família de origem, ou o encaminhamento para a adoção. Retomando aqui o aspecto histórico das instituições de acolhimento, segundo Oliveira (2014) e Rizzini e Rizzini (2004), antigamente, a rotina de uma instituição de acolhimento era bastante inflexível, as crianças e adolescentes não podiam sair da instituição nem para atendimento de saúde; e em relação à educação, estudavam no abrigo, na época chamado de internato.

Hoje em dia, podemos ver uma evolução quanto a isso. As crianças e adolescentes possuem mais autonomia, estudam em colégios próximos à instituição de acolhimento, fazem uso de transportes que as levam e as buscam na escola; já as crianças pequenas ainda precisam do acompanhamento de uma cuidadora/educadora. Os adolescentes já possuem a liberdade de ir a escola sozinhos e realizar algumas atividades fora das instituições de acolhimento com o consentimento do cuidador/educador, mas ainda há a necessidade de superar mitos, preconceitos 
e o desconhecimento desses espaços e suas especificidades na sociedade. Segundo Gulassa (2010 apud FONSECA; KELLY, 2016, p. 14-15):

Dizer que "o abrigo não deve existir" com ele existindo, cada vez mais cheio de crianças, é algo temeroso e perverso, pois o coloca num lugar de abandono - sem saída, impedindo sua transformação e impossibilitando o surgimento de um novo modelo de atendimento. Assistimos um quadro em que a instituição de abrigo se percebe negada pela sociedade, tal qual acontece com sua população. Lidar com o abandono pode trazer o risco de incorporá-lo em vez de transformá-lo. Trabalhar com situações de exclusão pode espelhar e repetir o lugar de excluído.

Corroboramos com o autor no que diz respeito ao cuidado que devemos ter ao negarmos a existência dos abrigos, pois são eles, em sua maioria, que acolhem as crianças e adolescentes que por diversos motivos foram afastados de suas famílias de origem. Entretanto,

Sobreviver sem verbas, colocar-se no papel de pedinte, alimentar-se das sobras ou do que está para vencer, ter dificuldade de ocupar uma casa na comunidade, ser empurrado para longe dos recursos culturais e sociais e, ao mesmo tempo, ser encarado como incompetente e inadequado - esse tem sido o difícil lugar ocupado pelos abrigos. Numa missão originalmente filantrópica e religiosa, os abrigos se identificam e repetem este lugar de carente e necessitado, e sua população mais uma vez revive o papel de vítima, menor, pobre, abandonada (GULASSA, 2010 apud FONSECA; KELLY, 2016, p. 14-15).

Infelizmente, o direito à proteção garantido em Lei, muitas vezes vem acompanhado desse olhar preconceituoso às crianças e adolescentes acolhidos, acarretando uma relação de favor, de benevolência e de caridade aos mais pobres e necessitados. Mesmo que os municípios mantenham algumas instituições de acolhimento, garantindo em tese os direitos das crianças, a verba é pouca para suprir a demanda. Em alguns casos, com o baixo repasse de verba, muitas instituições acabam encerrando suas atividades, transferindo as crianças e adolescentes que, por Lei, devem ficar na região onde possuem vínculos familiares, para instituições de acolhimento em cidades afastadas, ou até mesmo estados diferentes por não terem outra opção, acarretando uma descontinuidade de vínculos.

Por fim, destacamos que, independentemente do tipo de acolhimento - Acolhimento Institucional, Casa Lar ou Acolhimento Familiar -, é necessário que a criança e o adolescente recebam atenção e acompanhamento adequado, um tratamento de qualidade, conforme previsto em Lei. Nesse breve histórico, concluímos que, com o passar dos anos, mudanças nos serviços de acolhimento foram previstas por leis, mas infelizmente temos um descompasso entre a lei e a realidade. Ainda é um grande desafio a prestação de serviços de acolhimento que integrem os direitos das crianças e adolescentes de forma plena, garantindo-lhes o direito à convivência familiar e comunitária.

Infelizmente, no imaginário da maioria das pessoas, as crianças e adolescentes acolhidos ainda são vistos com resquícios de um tempo histórico, ou seja, órfãos, menores abandonados, pobres, delinquentes etc. E na escola não é diferente. Muitas vezes, esses alunos são vistos como crianças de abrigo, ora como coitados, ora como perigosos, alunos-problemas que colocam em risco o bom andamento da escola. Entretanto, cabe à escola não excluí-las, mas acolhê-las, garantindolhes o direito à educação e à convivência comunitária.

\section{A escola como espaço de socialização das crianças acolhidas}


Sabemos que, desde o nascimento, o indivíduo é exposto a situações que proporcionam aprendizado e desenvolvimento, e é na infância que essa aprendizagem tende a ser mais intensa, pois é o momento em que está mais curioso pelas descobertas. É com a socialização que a criança vai adentrar esse mundo de conhecimentos a serem adquiridos ao longo de sua vida. Ou seja, "o indivíduo passa por um processo de maturação dentro da sua própria cultura, através do qual aprende um conjunto de papéis e comportamentos sociais, normas e códigos de valores, que lhe permitem tornar-se um ser social" (MUSGRAVE, 1979 apud SANTOS, 2009, p. 9). Tal processo chama-se socialização e tem duas funções importantes: preparar o indivíduo para os papéis sociais "fornecendo-lhe o repertório necessário de hábitos, crenças e valores, padrões de reacção emocional e modos de percepção, bem como habilidades e conhecimentos requeridos. [...] é veículo de transmissão de cultura entre gerações, no sentido da sua persistência e continuidade" (MUSGRAVE, 1979 apud SANTOS, 2009, p. 9).

Para Santos (2009), há três tipos de socialização: a primária, vista como a família, a secundária, como a escola - instituição de formação -, e a terciária, que é o espaço público. Todas elas são um processo contínuo de extrema importância para o indivíduo na assimilação de hábitos, cultura e desenvolvimento próprio. A socialização primária faz parte da vida do indivíduo desde o seu nascimento, e é a família quem o ensina coisas básicas do dia a dia, como hábitos alimentares, higiênicos etc. A terciária traz o espaço público, as ruas e os meios de comunicação como principais agentes da socialização que acontece entre a criança e o meio com o qual ela está em contato. E a secundária, a qual deixamos por último por ser nosso objeto de estudo, consiste nas instituições escolares, que possuem o papel de favorecer o desenvolvimento cognitivo do aluno, acolhendo-o, ajudando-o na construção de sua identidade, assim como ensinando-o sobre os conhecimentos acumulados do mundo.

É na escola que se constrói parte da identidade de ser e pertencer ao mundo; nela adquirem-se os modelos de aprendizagem, na aquisição dos princípios éticos e morais que permeiam a sociedade; na escola depositam-se as expectativas, bem como as dúvidas, inseguranças e perspectivas em relação ao futuro e as suas próprias potencialidades (BORSA, 2007, p. 2).

Portanto, a escola tem um importante papel na vida das crianças institucionalizadas, pois, por medida protetiva, elas são afastadas de suas famílias, as quais são responsáveis pela socialização primária. Logo, caberá às instituições de acolhimento em parceria com a escola, trabalharem para que as crianças e adolescentes acolhidos possam ter, dentro do possível, uma formação completa em todos os sentidos.

A escola, para além de ter a função de estimular o desenvolvimento cognitivo e acadêmico da criança e do adolescente, deve ser também um espaço de inclusão destes nos meios sociais, "um processo dinâmico em que o indivíduo ou grupos minoritários e maioritários, se incorporam e compartilham a mesma estrutura social, promovendo o respeito mútuo pelas identidades sociais e culturais de cada um" (PERES, 1999 apud SANTOS, 2009, p. 27). A escola é imprescindível para o desenvolvimento e proteção da criança, contribuindo também para a formação de vínculos das crianças e seus pares, e das crianças com os adultos.

Em outras palavras, para além da sistematização de conteúdos, cabe à escola contribuir para a formação social do sujeito. A escola deve proporcionar um ambiente que favoreça a convivência comunitária, a socialização e a aprendizagem, bem como zelar por atenção e cuidados com seus alunos para a identificação e prevenção de situações de risco, tais como abandono, negligência, conflitos familiares, alcoolismo, drogadição e violência (física, sexual e psicológica). 
A palestra intitulada Judiciário e a Escola: qual o papel da escola em casos de crianças acolbidas e adotadas?, proferida pela Juíza da Vara da Infância e Juventude da Comarca de Londrina ${ }^{1}$, destaca os direitos das crianças e adolescentes. Também aponta as medidas protetivas a serem tomadas caso os direitos sejam violados, destacando a importância da formação da equipe escolar para que conheçam o Estatuto da Criança e do Adolescente, logo, os direitos intrínsecos nele. Nas palavras da juíza, "professores e demais profissionais que atuam na escola devem ser capacitados para o reconhecimento, prevenção e enfrentamento das diferentes situações de risco e vulnerabilidade que crianças e adolescentes estejam expostos" (CARDOSO, 2019, p. 11).

A formação desses profissionais é essencial para que eles possam identificar essas situações e prosseguir da melhor maneira, juntando o máximo de informações e acionando o Conselho Tutelar, que tomará as providências necessárias a fim de garantir a proteção e a segurança da criança e/ou adolescente. Nas palavras da juíza, "todos os integrantes desta grande rede, o que inclui a escola, possuem papel fundamental na proteção integral da criança e do adolescente, sendo responsáveis por seus atos e omissões, incluindo, na aceitação e empatia com o aluno que faz a verdadeira inclusão" (CARDOSO, 2019, p. 22).

Desse modo, faz-se necessária a oferta de conhecimento aos agentes educacionais sobre como identificar e agir quando da existência de alunos em situação de risco, evitando assim situações vexatórias para as crianças no contexto escolar. Falta também conhecimento sobre a adoção e a institucionalização de crianças e adolescentes, o que faz com que os profissionais da educação cometam erros, ocasionando a exclusão dos alunos acolhidos e/ou adotados em determinadas atividades escolares. Portanto, há necessidade de formação adequada aos agentes educacionais para se trabalhar a família, a adoção e a institucionalização, pois, na maioria dos cursos de formação inicial de professor ${ }^{2}$, não tem uma disciplina ou unidade que trabalhe o assunto com a atenção que ele merece.

Sendo assim, é na formação continuada que vemos a oportunidade de o professor, o diretor e o coordenador pesquisarem sobre o assunto e terem o conhecimento necessário para trabalhar com a criança acolhida institucionalmente e/ou adotada da melhor forma possível. É importante salientar que a procura por essa formação continuada deve ocorrer mesmo se não houver na escola um aluno adotado ou institucionalizado para que os mitos e preconceitos possam ser desconstruídos. Também é importante possibilitar a criação de um projeto dentro das escolas que mostre a relevância do respeito às diferentes constituições familiares, dentre elas, a família acolhedora e a família constituída por adoção.

Em entrevistas realizadas por Veloso, Zamora e Coutinho (2016), com um grupo de professoras sobre a adoção, observa-se na fala das profissionais o desconhecimento sobre o assunto, a dúvida de como tratar essa questão, assim como os estigmas criados culturalmente. Nas falas das entrevistadas, é possível constatar uma visão biologizante dos profissionais, a hereditariedade como responsável pelo fracasso escolar. O fato de a criança ou adolescente ser adotado ou estar em um abrigo não justifica por si só o fato de ele ter dificuldade em aprender, mas infelizmente professores encontram nessas situações a principal razão para justificar o fato do

\footnotetext{
${ }^{1}$ Dr. ${ }^{a}$ Camila Tereza Gutzlaff Cardoso, Juíza de Direito da Vara da Infância e Juventude do Foro Central da Comarca da Região Metropolitana de Londrina-PR, participou do Curso de Extensão "Escola, adoção, acolhimento institucional e formação de professores", da Universidade Estadual de Londrina, na qualidade de ministrante.

${ }^{2}$ A formação inicial de docentes para atuar na Educação Básica ocorre nos Cursos de Pedagogia e nos Cursos de Magistério em Nivel Médio, sendo o último, admitido como formação mínima para o exercício do magistério na Educação Infantil e no Ensino Fundamental I.
} 
não aprendizado do aluno, sem ao menos analisar seu próprio trabalho como professor e tentar de alguma forma ajudar o aluno.

As crianças e adolescentes institucionalizadas, assim como qualquer outro indivíduo da mesma idade, passam por crises em seu desenvolvimento, não devemos 'sentir pena', e sim conhecer e respeitar a sua história, se aproximar deles para ajudá-los. A maioria dos alunos acolhidos se desestabiliza por viver um 'tempo de espera' carregado de ambivalências e de incertezas, desejos e preocupações, tais como - retornar ou não a sua família de origem, ser adotado ou permanecer acolhido (D'ANDREA, 2012). "Ainda que de um modo diferente do de um adulto, também para a criança o futuro é fonte de esperança e de temores (D'ANDREA, 2012, p.82). Entretanto, o professor, muitas vezes, é quem poderá auxiliar essa criança e/ou adolescente, mostrando que se importa com ele, dando um novo significado para sua vida.

Mas, para que isso ocorra, será necessário que o professor conheça o aluno que está institucionalizado, a sua história, pois esses estudantes necessitam de um olhar cuidadoso, de acompanhamento durante seu processo de desenvolvimento escolar. Essa ação será facilitada caso a criança e/ou adolescente possua um diário de sua vida, que poderá ser acessado pelos professores para pensar a melhor forma de ajudá-los. Portanto, na instituição de acolhimento,

Devem ser organizados registros diários de cada criança e adolescente, nos quais conste relato sintético sobre a rotina, progressos observados no desenvolvimento, vida escolar, socialização, necessidades emergentes, mudanças, encontro com familiares, dados de saúde, etc. A equipe técnica do serviço de acolhimento deverá organizar prontuários individuais com registros sistemáticos que incluam: histórico de vida, motivo do acolhimento, data de entrada e desligamento, documentação pessoal, informações sobre o desenvolvimento (físico, psicológico e intelectual), condições de saúde, etc. [...] (BRASIL, 2009a, p. 14).

Observamos também uma certa dificuldade dos professores em trabalhar as datas comemorativas, conteúdos curriculares que envolvem a história de vida da criança acolhida ou adotada. Portanto, é necessário que o professor e a equipe pedagógica pensem da melhor forma um modo que não exclua essa criança e/ou adolescente; por exemplo, ao invés de pedir imagens de quando o bebê estava na barriga da sua mãe, peça uma imagem da 'família atual' - que pode ser com uma pessoa querida (madrinha, cuidadora etc.) ou com a família acolhedora. Essa ações também podem ser facilitadas com a produção do diário pela equipe técnica e cuidadores da instituição de acolhimento, que:

[...] devem garantir, ainda, a organização de um registro fotográfico de cada criança e adolescente, de modo a preservar 15 imagens do período em que estiveram acolhidos. No momento do desligamento esse registro deve fazer parte dos objetos pessoais que a criança ou adolescente levará consigo. Sempre que possível, a fim de promover um sentido de identidade própria, a criança e o adolescente - com o apoio de um cuidador/educador ou pessoa previamente preparada - devem ter a oportunidade de organizar um livro de sua história de vida que reúna informações, fotografias e lembranças referentes a cada fase de sua vida, ao qual poderão ter acesso ao longo do ciclo vital (BRASIL, 2009a, p. 14-15).

Esses fatos importantes da vida do indivíduo, quando anexados neste livro, irão facilitar o entendimento de sua identidade e auxiliar a escola, que conseguirá trabalhar os conteúdos curriculares que envolvem a história de vida e a família do aluno, de forma que a criança acolhida 
ou adotada não se sinta excluída, pois, como as outras crianças, irá possuir registros fotográficos e relatos de sua vida. Portanto, a instituição de acolhimento deve fazer esse registro, organizar-se para que isso aconteça mesmo com a dificuldade em fazer o acompanhamento de tantas crianças institucionalizadas, para que elas não percam sua identidade, conheçam sua história, afinal: "[...] Como construir um futuro se não há passado?” (ROSSETTI-FERREIRA et al., 2012, p. 396).

É de extrema importância que a criança e adolescente institucionalizados possam ter vivências fora da instituição de acolhimento e da escola, como qualquer outra criança e adolescente de sua idade, ajudando no desenvolvimento e na sua socialização, como "receber seus colegas nas dependências do serviço como participar, por exemplo, de festas de aniversário de colegas da escola. Em síntese, no convívio comunitário devem ser proporcionadas também experiências individualizadas" (BRASIL, 2009a, p. 16).

Sendo assim, essas crianças e adolescentes podem e devem ir para as escolas sozinhos ou com grupos de colegas, lembrando que as crianças pequenas devem estar sempre acompanhadas de um responsável, uma educadora ou algum agente da instituição de acolhimento. A pessoa responsável pela criança e adolescente, chamada de mãe social ${ }^{3}$, fará o acompanhamento dessa criança ou adolescente - quando da inexistência de um pedagogo na instituição de acolhimento -, irá comparecer às reuniões escolares e ajudá-lo em suas tarefas. Assim poderá ajudar os professores com as dúvidas referentes às crianças e adolescentes, estabelecendo uma parceria entre escola e instituição de acolhimento, que facilitará o desenvolvimento do educando.

Retomando o objetivo de demonstrar a importância da escola como espaço de socialização, bem como sua função junto às crianças acolhidas, destacamos a necessária parceria entre a escola e a instituição de acolhimento. Ainda são poucos os estudos referentes às crianças e adolescentes institucionalizados na escola, talvez pela invisibilidade social dessa clientela; entretanto, a condição desses meninos e meninas não os mantém trancados dentro da instituição de acolhimento. Como qualquer outro indivíduo de sua idade, eles têm o direito de socialização, de convivência comunitária e familiar, lembrando que a falta destes vai privar o desenvolvimento da criança e adolescente.

Portanto, é necessário que os profissionais da educação tenham uma formação adequada para a inclusão dessas crianças e adolescentes institucionalizados na escola, de forma que desmistifiquem os mitos e preconceitos sobre essa clientela, os respeitem e os ajudem, percebendo a melhor forma para trabalhar as questões curriculares referentes à hereditariedade e à constituição familiar, assim como as possíveis dificuldades de aprendizagem. Consideramos, ainda, que os professores precisam saber quem é o seu aluno, qual sua história de vida, para poder ajudá-lo da melhor forma possível e de maneira correta, amorosa, inclusiva.

\section{CONSIDERAÇÕES FINAIS}

O histórico das instituições de acolhimento no Brasil nos mostrou a evolução acerca da concepção de criança e da própria instituição, ou seja, da criança abandonada à criança cidadã, sujeito de direitos. Compreendemos, hoje, que os mitos e preconceitos sobre a criança e o adolescente acolhidos são resquícios de um tempo em que essas instituições atendiam as crianças pobres, filhos de mães solteiras, filhos ilegítimos considerados filhos do pecado, menores abandonados e deliquentes. Entretanto, temos hoje uma instituição de acolhimento que tem como função cuidar, proteger, acolher a criança e o adolescente, garantido-lhes o que lhes é de direito, inclusive a

\footnotetext{
${ }^{3}$ Nas Orientações Técnicas: Serviços de Acolhimento, tal função é denominada Educador Residente.
} 
educação e a convivência famíliar e comunitária. Logo, as crianças acolhidas estão na escola e, portanto, deve existir uma parceria entre a instituição de acolhimento e a escola, como o conhecimento sobre o andamento de sua adoção ou reinserção familiar, para que a escola possa ajudar nesse processo.

Mas qual o papel da escola com as crianças acolhidas? Compreendemos que seu papel é socializar a criança com os seus pares, ajudá-la a se perceber como indivíduo parte de uma sociedade; é desmistificar a visão de acolhimento como algo pejorativo e de criança como coitada; e dar importância à socialização e à construção da identidade. Então, o papel da escola vai além do que lhe compete, como sendo o espaço no qual a criança terá seu desenvolvimento cognitivo e acadêmico. É necessário que ela seja um espaço de inclusão, que proteja as crianças, identificando e prevenindo as situações de riscos, portanto, os professores devem estar atentos.

Por fim, destacamos a escassez de pesquisas sobre o tema aqui desenvolvido; desse modo, recomendamos a existência de trabalhos científicos sobre a infância, a escola e as instituições de acolhimento, para que possamos de fato reconhecer, olhar para essa parte da população infantil que também está na escola, muitas vezes, esquecida e marginalizada.

\section{REFERÊNCIAS}

ALEXANDRE, Tátia Mirellis de Oliveira. Representações sociais sobre família e abrigo: um estudo com crianças em situação de acolbimento institucional. 2017. 154 f. Dissertação (Mestrado em Psicologia Social), Universidade Federal da Paraíba, João Pessoa, 2017. Disponível em: https://repositorio.ufpb.br/jspui/bitstream/tede/9206/2/arquivototal.pdf. Acesso em: 13 set. 2018.

BORSA, Juliane Callegaro. O papel da escola no processo de Socialização Infantil. Psicologia.pt, [S. 1.], p. 15, jul. 2007. Disponível em: https://www.psicologia.pt/artigos/textos/A0351.pdf. Acesso em: 13 mar. 2020.

BRASIL. Decreto No 17.943-A de 12 de Outubro de 1927. Consolida as leis de assistencia e protecção a menores, DF: Presidência da República, [1927]. Disponível em: $\leq$ https://www.planalto.gov.br/ccivil 03/decreto/1910-1929/d17943a.htm $>$ Acesso em: 06/10/2018

BRASIL. [Constituição (1988)]. Constituição da República Federativa do Brasil de 1988. Brasília, DF: Senado Federal; Coordenação de Edições Técnicas, 2016. Disponível em: http://www.planalto.gov.br/ccivil 03/constituicao/constituicao.htm. Acesso em: 04 ago. 2019.

BRASIL. Lei no 6.697, de 10 de outubro de 1979. Institui o Código de Menores. Brasília, DF: Presidência da República, 1979. Disponível em: https://www2.camara.leg.br/legin/fed/lei/19701979/lei-6697-10-outubro-1979-365840-publicacaooriginal-1-pl.html. Acesso em: 25 jun. 2021.

BRASIL. Lei $n^{\circ}$ 8.069, de 13 de julho de 1990. Dispõe sobre o Estatuto da Criança e do Adolescente e dá providências. Brasília, DF: Presidência da República, 1990. Disponível em: http://www.planalto.gov.br/ccivil 03/leis/18069.htm. Acesso em: 06 out. 2018.

BRASIL. Resolução Conjunta no 1, de 18 de junho de 2009. Dispõe sobre as Orientações técnicas: serviço de acolhimento para crianças e adolescentes. Brasília, DF: Presidência da República, 2009a. Disponível em: http://www.mds.gov.br/webarquivos/publicacao/assistencia social/Cadernos/orientacoestecnicas-servicos-de-alcolhimento.pdf. Acesso em: 28 out. 2018. 
BRASIL. Resolução no 109, de 11 de novembro de 2009. Conselho Nacional de Assistência Social. Brasília, DF: Presidência da República, 2009b. Disponível em: https://www.mds.gov.br/webarquivos/public/resolucao_CNAS N109 \%202009.pdf. Acesso em: 10 mar. 2019.

BRASIL. Plano nacional de promoção, proteção e defesa do direito de crianças e adolescentes à convivência familiar e comunitária. Brasília, DF: Presidência da República, 2006. Disponível em: https://www.mds.gov.br/webarquivos/publicacao/assistencia social/Cadernos/Plano Defesa CriancasAdolescentes\%20.pdf. Acesso em: 28 out. 2018.

CARDOSO, Camila Tereza Gutzlaff. Judiciário e a Escola: qual o papel da escola em casos de crianças acolhidas e adotadas? Londrina, 27 ago. 2019, Apresentação em PowerPoint. 22 slides.

D'ANDREA, A. Tempo de espera: como vivem as crianças, o casal e os trabalhadores sociais à espera da adoção. Tradução de Luci Moreira da Costa. São Paulo: Instituto de Terapia Familiar de São Paulo - ITFSP, 2012.

FONSECA, Renato Luiz da Silva; KELLY, Roberta Ecleide de Oliveira Gomes. Acolbimento institucional: dos caminhos da história ao relato de experiência de atendimento de crianças e adolescentes na construção e perspectiva da autonomia. Acolbimento em Rede, [S. 1.], p. 1-26, 2016. Disponível em: https://www.fazendohistoria.org.br/s/ArtigoRenato.pdf. Acesso em: 23 out. 2018.

FUNDAÇÃO CASA. Governo do Estado de São Paulo: Fundação Centro de Atendimento Socioeducativo ao Adolescente (CASA), 2021. Disponível em: https://fundacaocasa.sp.gov.br/index.php/a-fundacao-casa. Acesso em: 20 maio 2021.

KREUZ, Sergio Luiz. Da convivência familiar da criança e do adolescente na perspectiva do acolbimento institucional: princípios constitucionais, direitos fundamentais e alternativas. 2011. 167 f. Dissertação (PósGraduação em Direito), Setor de Ciências Jurídicas, Universidade Federal do Paraná, Curitiba, 2011. Disponível em: https://www.acervodigital.ufpr.br/bitstream/handle/1884/29218/R\%20\%20D\%20-\%20SERGIO\%20LUIZ\%20KREUZ.pdf?sequence=1. Acesso em: 12 set. 2018.

MARCÍLIO, Maria Luiza. A roda dos expostos e a criança abandonada na história do Brasil: 17261950. In: FREITAS, Marcos Cezar de. (org.). História social da infância no Brasil. São Paulo: Cortez, 1997. p. 51-76.

MOURA, Clóvis. Dicionário da escravidão negra no Brasil. São Paulo: Editora da Universidade de São Paulo, 2004.

NAZARIO, Roseli. A infância das crianças pequenas no contexto de acolbimento institucional: narrativas de meninas e meninos na casa(lar). 2014. 260 f. Tese (Doutorado em Educação), Universidade Federal de Santa Catarina, Florianópolis, 2014. Disponível em: https://repositorio.ufsc.br/xmlui/bitstream/handle/123456789/129345/329235.pdf?sequence= 1\&isAllowed=y. Acesso em: 04 jun. 2021.

OLIVEIRA, 2014. Brincadeiras de Crianças Abrigadas - Estudo Etnográfico em Instituição de Acolbimento. 2014. 267 f. Tese (Doutorado em Educação), Instituto de Educação, Universidade Federal de Mato Grosso, Cuiabá, 2014.

RIZZINI, Irene; RIZZINI, Irma. A institucionalização de crianças no Brasil: percurso histórico e desafios do presente. Rio de Janeiro: Ed. PUC-Rio; São Paulo: Loyola, 2004.

ROSSETTI-FERREIRA, Maria Clotilde et al. Acolhimento de crianças e adolescentes em situações de abandono, violência e rupturas. Psicologia: Reflexão Crítica, v. 25, n. 2, p. 390-399, 2012. 
SANTOS, Ana Sofia Carvalho da Silva. (In)sucesso de crianças e jovens institucionalizadas. 2009. 165 f. Dissertação (Mestrado em Política Social), Instituto Superior de Ciências Sociais e Políticas, Universidade de Lisboa, Lisboa, 2009.

TORRES, Luiz Henrique. A casa da Roda dos Expostos na cidade do Rio Grande. BIBLOS, [S. 1.], v. 20, n. 1, p. 103-116, 2008.

VELOSO, Lúcia Fátima; ZAMORA, Maria Helena Rodrigues Navas; ROCHA-COUTINHO, Maria Lúcia. Crianças e adolescentes adotivos: como são vistos pela escola? Arquivos Brasileiros de Psicologia, Rio de Janeiro, v. 68, n. 2, p. 5-20, ago. 2016. Disponível em: http://pepsic.bvsalud.org/pdf/arbp/v68n2/v68n2a02.pdf. Acesso em: 7 jan. 2021.

\section{Informações das autoras}

Maria Vitória Braga Sudario

Universidade Estadual de Londrina (UEL).

E-mail: viivisudario@gmail.com

ORCID: https://orcid.org/0000-0002-1790-8045

Link Lattes: http://lattes.cnpq.br/0975378752018228

Gilmara Lupion Moreno

Universidade Estadual de Londrina (UEL).

E-mail: gilmaralupion@hotmail.com

ORCID: https://orcid.org/0000-0002-4435-878X

Link Lattes: http://lattes.cnpq.br/1002035563058958 